\title{
UVA Method - innovative approach in economic and strategic management of an enterprise
}

\author{
Dragomirescu Simona Elena, University Lector, PHD Candidate \\ University of Bacau \\ Solomon Daniela Cristina, University Lector, PHD Candidate \\ University of Bacau
}

\begin{abstract}
:
UVA method has developed starting from the principle "measuring the entire activity of an enterprise with a single unit measure", announced by Georges Perrin at the beginning of the '50's. The followed aim is that the method would be simple and, respectively, would avoid the global costs treating. As consequence, a minute analysis is needed for every unit of the process. Also, a fundamental principle is imposed: the costs of these activities will generally remain established in relative values at least for the period when major changes in technology do not occur.
\end{abstract}

\section{Key-words:}

modern methods of costs

\section{Concepts defining}

As well as Georges Perrin method, UVA ${ }^{1}$ method is an indexes procedure, with the meaning that uses for enterprise's activity measuring and costs determination a nonmonetary unit measure, represented by an index, an equivalent, a characteristic number etc. According to Yves Levant and Olivier De La Villarmois, any indexes method is based on the idea of reducing an multi/products/activity enterprise to a single product one or with a low number of family products from the point of view of accountancy analysis; therefore, the production assembly is reduced to a multiple of a standard article, these equivalences being considered stabile.

The objectives followed by UVA method are:

$>$ determination of products costs and margins administration;

$>$ understanding of the process "how do we produce and how do we sell";

$>$ measuring of value added by every step;

$>$ benefit or loss measuring on most elementary level (every realized transaction). It arises that the method "emphasizes the strategic use of costs" and "may make place to some developments that proceed from interesting simulations of strategic plan". 2

UVA method is based on creation of a measuring method for value added - UVA - for all functions of an enterprise, using the following reasoning: ${ }^{3}$

$>$ enterprise shaping by work "ranges" description for all functions;

${ }^{1}$ UVA means Unités de Valeur Ajoutée - Value Added Unit.

${ }^{2}$ Bouquin H. - „Comptabilité de Gestion”, Economica, 2000, p. 97.

${ }^{3}$ Dumitru M., Calu D.A. - "Administration Accounting and Costs Calculation”, Contaplus Publish house, Ploieşti, 2008, p. 214. 
$>$ affecting, for every labour place, resources consumption, on the basis of a technical-economic analysis;

$>$ creation of the unit measure of value added - UVA - and calculation for every labour place expressed in UVA indexes, aspect that transforms a multiproducts activity enterprise in mono-product activity one;

$>$ valorisation of every product/activity in "UVA equivalents".

There should be underlined the fact that "value added" expression does not have the same meaning as for financial accountancy, but it is referred to, for instance, in the case of a product, to the consumed resources assembly to reach the finite product stage, or, in other words, all efforts of conceiving, industrialising, production, stocking etc.

\section{UVA method phases}

Adopting the UVA method supposes the covering of two phases: method's construction and exploiting.

\section{(1) Method construction}

The functioning of an enterprise corresponds to a network of ranges that is necessary to be shaped for a precise understanding. A range represents a sequence of elementary operations or tasks realised in a certain time span in labour places that operates under certain technical/economic conditions and where a precise established quantity of products is consumed.

UVA method divides the expenses of an enterprise in three major categories: $\square$ expenses for products processing; $\square$ expenses for clients' services performing; $\square$ expenses for general enterprise's functioning.

On the basis of a minute and punctual analysis of an enterprise the UVA valorisation of every realised transaction is followed, respectively of fabricated products, administrative, commercial and logistics ranges connected to the attended clients. The followed aim is reducing non-attributable expenses to minimum (to less than $10 \%$ from the total of expenses).

Therefore, the UVA method construction supposes the establishing of the value added expressed in attributable value unit for:

$>$ each product, still from its projection, industrialization, production ranges;

$>$ each service given to client, analyzing the administrative, commercial and logistics ranges.

The method's construction's period is 4-6 months and supposes the covering of the following phases:

(a) UVA posts inventory. An enterprise is formed of labour posts, that represent an assembly of material and human means that suppose resources consumption. $\boldsymbol{A}$ UVA post represents a labour post that functions with precise determined resources consumption. Their inventory should be realized any time that changes occur in resources consumption size or posts are reorganized.

(b) defining an entity for value measure. Taking into consideration the specific of every enterprise, a measure unit for value added (UVA) will be defined, which can be the most sold product, one of the most performed services etc. UVA is independent from monetary variation, consisting in reality from an operation manner or from an amount of operation manners at a certain $t$ moment. This aspect leads to a simplification of enterprise's accounting that, therefore, will produce and sell a single product $\rightarrow$ UVA (value units).

(c) UVA posts evaluation in units. Each UVA post will be expressed in units by comparison with the reference post, respectively by comparing direct consumed resources (without arbitrary apportion key) at a $t$ moment, under normal exploitation conditions. In order to realise this comparison, all resources will be 
expressed in monetary units on the basis of data from accountancy and/or technical and economic data.

(d) resources evaluation. In this phase, the whole of enterprise's resources should be allocated to labour posts, separating the expenses in expenses with materials, equipments, maintenance, staff expenses, material base usage expenses etc. After this analysis, approximately $90 \%$ from total expenses become direct ones, nonimputable expenses being reduced to minimum. For every separate post will be established a normal activity volume, it resides that to each post a direct resources consumption on assignation unit will revert, named post rate.

(e) determination of UVA indexes afferent to posts. UVA posts cost will be determined in value added unit (UVA). The value added unit represents the resources consumption necessary for a post/process/product chosen as representative for the entire activity of the enterprise. This representative post/process/product is considered as basis, and is capitalisation is named basis rate. The sum between post rate of every posed used by UVA and post usage time allows the UVA operation manner evaluation. From here the UVA post index ${ }^{4}$ can be established as report between its resources consumption and the one of base process (post rate/basis rate).

(f) establishing of UVA equivalents of products and processes. It is known that in an enterprise, every product and, respectively, service represents the consumers of operations realised in UVA posts at a certain $t$ moment, taking into consideration the fact that a product results form a succession of ranges of conceiving, production, control, while a service results from a succession of administrative, commercial, logistics etc. ranges. As a consequence, every product/service represents UVA consumers. In order to establish their equivalents in $\mathrm{UVA}^{5}$, there will be first established the UVA equivalents for ranges from where it results:

\begin{tabular}{|c|c|c|c|c|}
\hline $\begin{array}{c}\text { UVA equivalents of } \\
\text { a range }\end{array}$ & $=$ & $\begin{array}{r}\sum \text { mobilised UVA } \\
\text { posts index }\end{array}$ & $\mathrm{x}$ & $\begin{array}{c}\text { Mobilisation } \\
\text { time }\end{array}$ \\
\hline $\begin{array}{l}\text { UVA equivalents of a } \\
\text { product/servic }\end{array}$ & & $\begin{array}{r}\sum \text { UVA eq } \\
\text { rang }\end{array}$ & & $\operatorname{ary}$ \\
\hline
\end{tabular}

(g) calculation of UVA equivalent of a sell. Once established the UVA equivalent for products/services, the UVA equivalent of a sell/invoice can be established. The total cost of a sell is made of the sold products/services $\operatorname{cost}^{6}$, to which the clients imputable cost is added ${ }^{7}$.

UVA equivalents of a
sell $\quad \sum$ UVA equivalents of a products/services mobilised by

${ }^{4}$ The UVA post index presents the major characteristic that it remains stable in time at least as long as the labour post or the resources consumption is not changed.

${ }^{5}$ As well as UVA indexes, UVA equivalents remain stable for as long as changes in UVA posts or operative ranges do not occur

${ }^{6}$ The costs of sold products or services include all costs with row materials, services and other incorporated purchases to which value added cost is added by enterprise.

${ }^{7}$ The costs imputable to clients comprises specific clients costs (with transport, wrapping etc.), to which the value cost added by enterprise to client is added, respectively the commercial cost (prospecting, documentation etc.), administrative cost (recording, invoicing etc.) and logistics cost (hoarding, delivery etc.). 
Diagrammatic, construction phase of UVA method can be represented as follows:

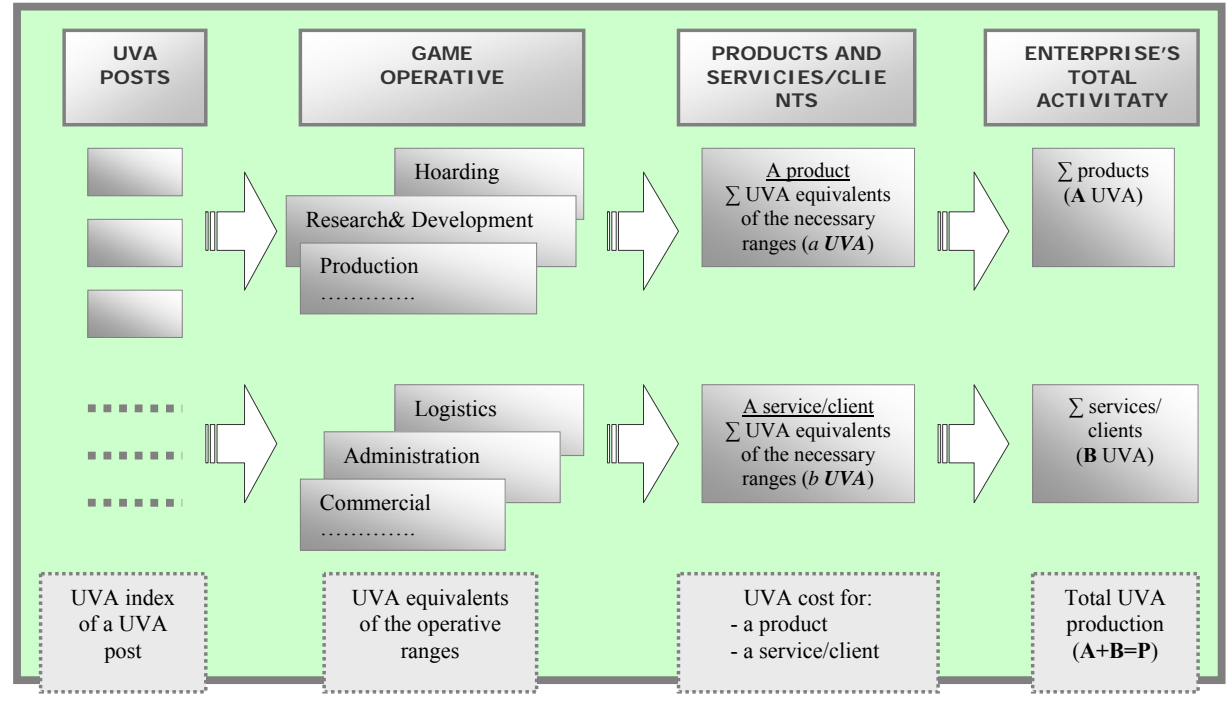

Figure 1. Graphical representation of UVA construction phase method Source: http://www.crefige.dauphine.fr/pedagogie/UVA/UVAnet.htm

\section{(2) Method's exploitation}

In this phase of UVA method's exploitation, the followed objectives are:

$>$ determination of products/clients/invoices etc. costs;

$>$ establishing the performance indices and of dashboards that allow the knowledge, in any time, of costs evolution, production and profitableness;

$>$ determination of result apart for every transaction and outlining of profitableness curve;

$>$ formulation of long/short term decisions with the purpose of profit's amelioration, perennial insurance and enterprise's development.

Method's exploitation period is 3-4 months and supposes the covering of the following phases:

(a) measuring of the produced value added. For every product/service of an enterprise, no matter that is referred to production side, administrative, logistic, commercial etc., how many value added units are produced is measured. By their summing the value added produced at a certain $t$ moment at the enterprise level is determined:

\section{Total production $\quad=\quad \sum$ UVA equivalents of products/services} in UVA realised in a $t$ period

(b) UVA cost calculation. The cost of a UVA is determined for every period, on the basis of data from general accounting from where the purchases incorporable in products and the expenses specific to clients are eliminated. As consequence, the calculation relation is:

$\underset{\text { UVA }}{\text { Cost }}=\frac{\mathrm{C}-(\mathrm{A}+}{\mathrm{D})}$

$$
\begin{gathered}
\mathrm{C} \text { - the sum of expenses from general } \\
\text { accounting } \\
\mathrm{A} \text { - the sum of purchases incorporable in }
\end{gathered}
$$
products 


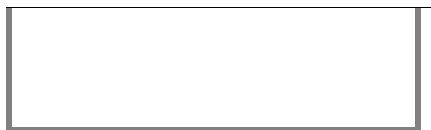

$$
\begin{gathered}
\text { D - expenses specific to clients } \\
\text { QuVA - the UVA production at a certain } \\
\text { moment } t
\end{gathered}
$$

The UVA cost, once determined, will show the better or worse conditions where the enterprise developed its activity.

(c) determination of production costs of a sell and its result. Production cost of a sale is calculated by summing: $\square$ UVA equivalent of the respective sale evaluated in UVA cost; $\square$ expenses incorporable in products; $\square$ expenses specific to clients. Comparing the production cost of sale with the value of the respective invoice/sale, the generated result is determined. The calculation relations are:

\begin{tabular}{|cccc}
$\begin{array}{c}\text { Produc } \\
\text { tion }\end{array}$ & $\begin{array}{c}\text { UVA equivalents of sales } \mathrm{x} \\
\text { UVA cost }\end{array}$ & $+\begin{array}{c}\text { Expenses incorporated } \\
\text { in products }\end{array}$ & $\begin{array}{c}\text { Expenses } \\
\text { specific to } \\
\text { costs }\end{array}$ \\
of a & & & \\
sale & & & \\
\hline
\end{tabular}

Sale result $=$ Invoice/sale value $\quad-\quad$ Sale production cost

The value added production for a certain $t$ period represents the UVA sum of products/clients in that period:

$\mathrm{Q}_{\mathrm{UVA}}=\mathrm{QP}_{\mathrm{UVA}}+$
$\mathrm{QC}_{\mathrm{UVA}}$

Production realised from a $i$ article is established starting from the produced quantity multiplied with UVA production equivalent of respective article:

$\mathrm{qp}_{\mathrm{iUVA}}=\mathrm{qp}_{\mathrm{i}} \times \mathrm{E}_{\mathrm{i}}$

Similarly, total production of services invoiced to clients is determined:

$$
Q C_{U V A}=\sum_{j=1}^{m} q C_{j U V A}
$$

The service delivery for $j$ client is established as follows:

$$
\begin{gathered}
q c_{j} \text { UVA } \\
=\underset{u V A}{q c_{j}} \times E_{j} \\
\text { und }
\end{gathered}
$$

(d) sales profitableness analysis. The results obtained following the sales from an exercise, expressed in absolute value and/or in relative value, may be graphically represented by means of sales profitableness curve, where the starting point is represented by the sale for which the higher loss is registered, while the final point is represented by the sale for which the higher profit is obtained. The UVA method allows the outlining of profitableness curve not only for total sales but also detailed for a client of on total clients/products or groups of products or on geographical areas/distribution channels/sales representatives / sales market etc. (with an average profitableness and visual and numerical dispersion). On the basis of analysis of profitableness structure for every element pertinent for enterprise, managers build their action plans, evaluate obtained results, formulate solutions for low sales to become profitable etc. Specialists consider that in practice as well as in specific literature, sale cost and result is more pertinent information than global profitableness for a client/ distribution channel.

(e) creation of an administration system. In the support of enterprises that apply UVA method an informatics program is brought realized by creators of UVA 
calculation method, program that will allow method's exploitation. By means of this program, called Profit Scanner, managers may visualize, at any moment, profitableness curves on every product/client/geographical area etc., may realize classification of sales, errors' highlighting.

\section{In stead of conclusions ... arguments in favour of UVA method}

From the above presented aspects, it resides that UVA method represents an instrument used by management in decisions' fundament. It comes for the support of costs administration control, with the purpose of enterprise' profitableness management's amelioration, because the method:

$\vartheta$ allows the evaluation in value added units (UVA) for every sale/invoice and calculation of the transaction result - tracing the profitableness curve, the enterprise management team may analyze the sale situation and may intervene in their structure in order to ameliorate the obtained results;

2 helps to creation of performance indicators and dashboards implementation aspect that leads to knowing and permanent following and at any moment of costs, production, profitableness evolution;

$\supset$ becomes an instrument of assistance for strategic decision - by means of prediction simulations that it allows;

$\rightarrow$ is useful in the case of complex enterprises ${ }^{8}$, of any size and activity sector;

- assures, due to a minute analysis, non-imputable expenses reduction to less than $10 \%$ from the total expenses, as consequence the difficulty of incorporating expenses in costs is eliminated on the basis of certain arbitrary repartition keys;

$\partial$ answers to problems concerning the difficulty of settling reliable sale prices, margins tighter and tighter due to concurrence intensification;

$\vartheta$ is based on the data provided by general accounting, which means that its implementation does not need a complex and expensive informatics system;

$\rightarrow$ supposes implementation, exploitation and maintenance reduced cost; if changes in labour posts structure or in resources consumption do not occur, the UVA analysis actualisation is useless to be recovered earlier than 4-5 years.

\section{Bibliography:}

1. Bouquin, H. (2000), Comptabilité de Gestion, Economica

2. Dumitru, M., Calu, D.A. (2008), Administration Accounting and Costs Calculation, Contaplus Publish house, Ploieşti

3. http://www.crefige.dauphine.fr/pedagogie/UVA/UVAnet.htm.

\footnotetext{
${ }^{8}$ The heterogeneity of an enterprise may arise either from products' diversity or from the one of clients, consumed resources, sales conditions, distribution channels, production means etc.
} 